\title{
BRASILIA EN EL ESPEJO DE LA PLANIFICACIÓN ${ }^{1}$ BRASÍLIA NO ESPELHO DO PLANEJAMENTO BRASILIA IN THE PLANNING MIRROR
}

Recebido em 23/02/2021. Aceito em 16/04/2021.

\author{
GORELIK, Adrián \\ Consejo Nacional de Investigaciones Científicas y Técnicas de Argentina y Centro de Historia Intelectual, \\ Universidad Nacional de Quilmes. Buenos Aires, Argentina. \\ adrian.gorelik@gmail.com \\ ORCID: 0000-0002-9198-7597
}

\footnotetext{
1 En una versión reducida, este texto fue presentado en la Mesa "Brasília aos 60: leituras contemporâneas", Seminario virtual preparatorio del VI ENANPARQ, 13 de octubre de 2020; agradezco a Carolina Pescatori la invitación a publicarlo. Con excepción de pequeños cambios para su adecuación como artículo independiente, el texto integra mi libro, actualmente en prensa, La ciudad latinoamericana: una figura de la imaginación social del siglo XX (Buenos Aires, Siglo XXI Editores); Brasilia entra allí como "desvío por la arquitectura" dentro de un recorrido por la planificación urbana y territorial en América Latina. Las primeras partes del texto retoman y expanden argumentos que ya presenté en un artículo anterior: "Sobre a impossibilidade de (pensar) Brasília", Serrote № 10, Revista del Instituto Moreira Salles, Río de Janeiro, marzo de 2012; la última parte, sobre Mario Pedrosa, fue concebida íntegramente para esta ocasión. Agradezco la lectura atenta de Carlos Martins que contribuyó a la definición de la versión final.
} 


\title{
Resumen
}

Una de las paradojas que ha enrarecido la comprensión de Brasilia es que la empresa de mudar la capital pareció hecha a la medida de la planificación desarrollista, al tiempo que todos los pormenores de su proyecto y realización la muestran como el producto por excelencia de la cultura arquitectónica, contradiciendo punto a punto aquel ethos planificador. Lo primero explica el entusiasmo de tantos que la entendieron como la encarnación más plena de una ambición político-territorial sustancial para una transformación progresista de América Latina, mientras que lo segundo sustenta el desconcierto e incluso el repudio de tantos, ante la ausencia de cualquier esbozo de programa urbano-territorial. Analizando debates de los años sesenta en Brasil y América Latina, en el artículo se busca comprender qué muestra esta paradoja tanto de Brasilia como de la planificación, haciendo hincapié en la interpretación de dos analistas clave del período, Jorge Wilheim y Mario Pedrosa.

Palabras clave: Brasilia, planificación, arquitectura, historia intelectual

\section{Resumo}

Um dos paradoxos que tem dificultado o entendimento de Brasília é que a empreitada de mudar a capital parecia feita sob medida do planejamento desenvolvimentista, enquanto todos os detalhes de seu projeto e implantação a mostram como o produto quintessencial da cultura arquitetônica, contradizendo ponto por ponto esse ethos de planejamento. A primeira explica 0 entusiasmo de tantos que a compreenderam como a encarnação mais plena de uma ambição político-territorial substancial por uma transformação progressista da América Latina, enquanto a segunda sustenta a confusão e mesmo a rejeição de tantos, na ausência de qualquer esboço de programa urbano-territorial. Analisando os debates dos anos 60 no Brasil e na América Latina, o artigo busca compreender o que esse paradoxo mostra tanto em Brasília quanto no planejamento, enfatizando a interpretação de dois analistas-chave do período, Jorge Wilheim e Mario Pedrosa.

Palavras-chave: Brasília; planejamento; arquitetura; história intelecutal

\begin{abstract}
One of the paradoxes that has made the understanding of Brasilia rare is that the enterprise to move the capital seemed to be tailored to developmental planning, while all the details of its project and implementation show it as the quintessential product of architectural culture, contradicting point by point that planning ethos. The first explains the enthusiasm of so many who understood Brasilia as the fullest incarnation of a substantial political-territorial ambition for a progressive transformation of Latin America, while the second sustains the confusion and even the rejection of so many, in the absence of any outline of urban-territorial program. Analyzing debates of the sixties in Brazil and Latin America, the article seeks to understand what this paradox shows both about Brasilia and planning, emphasizing the interpretation of two key analysts of the period, Jorge Wilheim and Mario Pedrosa.
\end{abstract}

Keywords: Brasilia, planning, architecture, intellectual history 


\begin{abstract}
"O planejamento de Brasília discorda, aparentemente, de todos os conceitos, cânones e diretrizes adotadas pelo Govêrno, firmas e profissionais. Com efeito, a cidade foi erigida artificialmente, sem plano integrado, sem análise sócio-econômica, sem equipe integrada e inter-disciplinar, sem investigação de qualquer prognóstico, sem grupo local motivador e sem fornecer qualquer programação imediata ou escalonada. E deu certo",
\end{abstract}

Jorge Wilheim, $1969 .^{2}$

\begin{abstract}
"A sabedoria de Lúcio Costa consistiu em aceitar a incongruência inerente ao programa, e, evitando toda solução de meio-termo, ou eclética, decidir resolutamente pelo lado inexorável, dadas as condições objetivas imediatas: o reconhecimento pleno de que a solução possível ainda era na base da experiência colonial, quer dizer, uma tomada de posse à moda cabralina, chanfrando na terra o signo da cruz ou numa evocação mais 'moderna' e otimista, fazendo pousar docemente sobre a sua superfície, a forma de um avião",
\end{abstract}

Mario Pedrosa, $1957 .^{3}$

¿Qué imagen nos devuelve de Brasilia el espejo de la planificación? Lo primero que puede decirse es que surge una figura ambivalente o paradójica: la empresa de mudar la capital parece hecha a medida de la planificación desarrollista, y eso explica el entusiasmo de tantos que la vieron como la encarnación mayor de una ambición político-territorial sustancial para una transformación progresista en América Latina; al tiempo que los pormenores de su realización contradicen aquel ethos planificador punto a punto, y de allí el desconcierto que muestra Wilheim en la cita inicial, y el repudio de tantos más, ante la ausencia de cualquier programa urbano-regional.

Luego de un largo período en que Brasilia y la planificación recorrieron sendas críticas e historiográficas casi incomunicadas, en los últimos años se vienen desarrollando varios trabajos que han buscado reestablecer esas relaciones, mostrando los puntos de contacto de la empresa de mudanza de la capital con las políticas desarrollistas de Kubitschek, planteando relaciones con los proyectos industriales (especialmente de la industria automovilística), con SUDENE y la planificación económica más general. ${ }^{4}$ Son trabajos muy importantes para entender el período, pero el análisis de las fuentes de época permite seguir sosteniendo que esas relaciones no formaron parte del debate de entonces sino muy excepcionalmente, y en todo caso de forma negativa, viendo a Brasilia como obstáculo de una verdadera planificación. Desde el punto de vista de una historia de las ideas sobre la planificación urbana, entonces, parece productivo partir de aquella paradoja.

En rigor, podría pensarse que de este modo se elige un punto de partida convencional: siempre supimos que Brasilia fue un producto de la cultura arquitectónica. Alcanza con compararla con Ciudad Guayana, el gran emprendimiento planificador del período, para notar sus gigantescas diferencias. Mientras que Ciudad Guayana encarna algunas de las tendencias más avanzadas

\footnotetext{
2 Jorge Wilheim, "Brasília 1969: um comentário indispensável", en Urbanismo no subdesenvolvimento, Rio de Janeiro, Editôra Saga, 1969, p. 384.

${ }^{3}$ Mario Pedrosa, "Reflexões em torno da nova capital" [1957], en Dos murais de Portinari aos espaços de Brasília (organizado por Aracy Amaral), São Paulo, Perspectiva, 1981, p. 307.

${ }^{4}$ Me refiero a trabajos como los siguientes: Antonio Carlos Carpintero, Brasília: prática e teoria urbanística no Brasil, 1956-1998, tesis de doctorado FAU-USP, 1998; Celso Lafer, JK e o Programa de Metas (19561961): processo de planejamento e sistema político no Brasil, Río de Janeiro, Editora FGV, 2002; Rodrigo de Faría y Antonio Carpintero, "Brasilia, Capital del Brasil: desarrollo nacional y urbanismo (1930 - 1960)", en Carlos Sambricio, Ciudad y vivienda en América Latina: 1930-1960, Madrid, Lampreave, 2012; Izadora Carvalho Laner, "Planejamento regional e desenvolvimento no Brasil: 1955-1961", tesis de Maestría, Faculdade de Arquitetura, Universidade de Brasilia, 2018 (agradezco a Rodrigo de Faría que me dio a conocer esta interesante tesis).
} 
en el abordaje científico del proyecto urbano, buscando integrar a través de equipos interdisciplinarios todas las variables posibles de la planificación, desde la economía y las ciencias sociales al diseño, Brasilia, lo sabemos, fue concebida por una única mente inspirada, que compitió en el concurso apenas con una serie de bosquejos a mano alzada y una breve memoria descriptiva de entonaciones líricas. Y si bien todavía en 1956, cuando el concurso para la nueva capital fue convocado, estaba muy presente el ejemplo de Chandigarh, la capital del Punjab que Nehru le había encargado cinco años antes a Le Corbusier, ya comenzaba a debilitarse mucho la confianza en el talento arquitectónico para la creación de ciudades, ante la convincente potencia de los enfoques sistemáticos de la planificación. Reyner Banham escribió en 1962 que Brasilia era "una ciudad como todavía sueñan los arquitectos en las novelas": apenas dos años después de su inauguración, también para alguien que como Banham no ocultaba su aprecio por la nueva capital de Brasil, ya parecía un caso de alucinación disciplinar, más que un ejemplo en condiciones de dialogar con la vanguardia de la planificación urbana. ${ }^{5}$

Como se ve, el abordaje en sí del problema puede no ser original, pero lo que sí lo es en ese contexto es la interrogación misma sobre ese desacople entre Brasilia y la planificación, la indagación en sus relaciones paradójicas, porque ellas han terminado por naturalizarse, sin integrarse a su historia (la de ambas). Si lo que nos muestra el análisis de la historia intelectual es que siempre formaron parte de relatos diferentes, no alcanza con recuperar sus vinculaciones "objetivas", como hace aquella nueva literatura historiográfica; creo que es necesario, para entender mejor a ambas, comprender cómo se apreciaban entre ellas, qué puntos ciegos de cada una es posible identificar en la imagen que nos devuelve de la otra.

Partamos entonces de la confirmación de que el proyecto de Lucio Costa no pertenecía al mundo de la planificación, tal cual había comenzado a entenderse en los años 1950, es decir, un modo de reflexión y acción sobre la ciudad y el territorio de carácter "interdisciplinario", con fuerte anclaje en las ciencias sociales, desde la geografía a la sociología pero con predominio de la economía, con el objetivo de lograr, en los sintéticos términos de Corboz, una distribución ideal de las personas, los bienes y los servicios sobre un territorio dado. ${ }^{6}$ El proyecto de Costa ni siquiera puede colocarse dentro de la acepción ya dominante en la tradición urbanísticoarquitectónica-ingenieril que desde la segunda posguerra había incorporado el espíritu analítico y los procedimientos de la planificación urbana y regional británica, un proceso que en Brasil tuvo manifestaciones todavía más tempranas, como mostró Sarah Feldman para el caso de los contactos con el planning norteamericano de Anhaia Melo, figura central en aquella tradición y en su establecimiento en las administraciones municipales y la enseñanza universitaria. ${ }^{7}$ Eso es lo que señala desde el acápite la frase de Jorge Wilheim: el proyecto ganador no tuvo nada "de todos os conceitos, cânones e diretrizes" de la planificación, nos dice, y sin embargo, "deu certo", tuvo éxito, no en el sentido más banal, el de la eficacia para ganar el concurso, sino porque acertó con la respuesta que el desafío de levantar la nueva capital comportaba. Eso es lo que proponemos aquí: intentar entender las razones -y las consecuencias- del lugar tan excéntrico de Brasilia en el debate planificador, no sólo brasileño, sino latinoamericano, justo la ciudad que a pesar de todo sigue ilustrando como casi ningún otro hecho urbano-territorial del período la empresa desarrollista.

\section{Una ciudad política}

Comencemos por analizar las verdades comprendidas en ambas partes de la paradoja. Que la empresa misma de construir la nueva capital en el interior parece hecha a medida de la planificación desarrollista, surge ya del análisis de la figura del propio Juscelino Kubitschek, primer candidato a la presidencia del Brasil -y uno de los primeros en América Latina- en

\footnotetext{
${ }^{5}$ Reyner Banham, Guide to Modern Architecture, D. Van Nostrand, 1962, p. 136.

${ }^{6}$ André Corboz, "El urbanismo del siglo XX: un balance" [1992], en Orden disperso. Ensayos sobre arte, método, ciudad y territorio [1998], Bernal, Editorial de la Universidad Nacional de Quilmes, 2015.

7 Ver Sarah Feldman, Planejamento e zoneamento. São Paulo 1947-1972, São Paulo, EDUSP, 2005, especialmente el capítulo "O Departamento de Urbanismo e a Institucionalização do Planejamento".
} 
poner la planificación como eje de una campaña electoral. Con el trauma del suicidio de Vargas enturbiando todavía el clima político y el ánimo social, Kubitschek se empeñó durante toda la campaña de 1955 en presentar la planificación como un instrumento decisivo para perseguir el desarrollo y la justicia social, mostrando su candidatura como parte de un proyecto reformista moderno y eficaz. ${ }^{8}$ El plan nacional de desarrollo, que llamó Plano de Metas, iba a ser el encargado de que Brasil progresara "cincuenta años en cinco", como sostenía el lema de campaña, a través de la construcción de infraestructuras capaces de permitir un salto industrializador en todo el país, especialmente a través de la extensión de la energía y el transporte. Aunque la construcción de Brasilia no figuraba en las 30 metas del plan, la nueva capital fue incluida con ingenio como la "meta-síntesis", el gran hecho representativo de la nueva fisonomía deseada para la nación, en la cual el doble desbalance geográfico, el que impusieron la Colonia hacia el litoral y el poderío paulista hacia el sur, se combatía con una integración territorial y socio-económica que fijaba su baricentro en el interior remoto y postergado. De hecho, como se sabe bien, la ambición de recentramiento del Brasil formaba parte de la larga mitología de la frontera, la "Marcha hacia el Oeste" reactualizada una y otra vez en el imaginario social brasileño. ${ }^{9}$ En los términos específicos de la mudanza de la capital, esa ambición se apoyaba en un antecedente simbólico, la propuesta de José Bonifacio, en 1821, para instalar la capital en el interior, y uno legal, fijado en la primera constitución republicana de 1891, que definió el área de radicación en el Planalto Central, una invocación y un sitio que iban a reiterarse, más allá de variaciones y disputas, en todos los textos constitucionales posteriores y en todas las expediciones de reconocimiento. ${ }^{10}$ De ahí que en un simposio sobre Brasilia realizado en la Universidad de Toulouse en 1964, el geógrafo Jean Roche pudiera presentar a la nueva capital como la consumación de la transformación voluntarista de la geografía política nacional, una "impulsión creadora" que debía verse como "el catalizador del desarrollo y el símbolo del desarrollismo, es decir, de una teoría del desarrollo pensada como elemento motor, no solamente de la economía sino de la psicología nacional brasileña". ${ }^{11} Y$ esta doble presencia de la planificación en la política, como sinónimo de eficiencia técnica para garantizar las expectativas futuras y de argamasa cultural para instituir una épica nacional-desarrollista no es sólo brasileño, mostrando una tendencia regional en las disposiciones con que se incorporaban las ideas de planificación y desarrollo.

¿Es tal acepción culturalista de la planificación lo que devuelve al centro a la arquitectura, dando lugar a la segunda parte de la paradoja? Esto también está presente en convicciones del propio Kubitschek:

Desde cedo compreendi que a arquitetura moderna era para o Brasil mais do que uma tendência estética, e sobretudo mais do que a projeção de um movimento universal no seio da nossa cultura. Na verdade [...] ela se projeta como vigorosa força de afirmação cultural $[\ldots] .^{12}$

Ya en su gestión como prefecto de Belo Horizonte (1940-45) había establecido una fructifera liaison con Oscar Niemeyer, quien realizó en el conjunto lacustre de Pampulha uno de los hitos fundacionales en la proyección internacional de la arquitectura brasileña, ratificando a escala local los altos réditos políticos que la entente estado-arquitectura moderna había comenzado a pagar en la escala nacional desde la construcción del Ministerio de Educación en Rio de Janeiro en 1937. La liaison continuó muy activa durante su gobernación en Minas Gerais

\footnotetext{
${ }^{8}$ Cfr. Celso Lafer, JK e o Programa de Metas..., op. cit.

${ }^{9}$ Ver Candice Vidal e Souza, A patria geográfica. Sertão e litoral no pensamento social brasileiro, Editora UFG, Goiânia, 1997.

${ }^{10}$ Las innúmeras publicaciones sobre Brasilia de la época de su construcción suelen incluir una sección sobre los antecedentes, presentados como pedigree y justificación histórica de la nueva capital; un buen análisis, en Jeferson Tavares, Projetos para Brasília: 1927-1957, Brasilia, Iphan, 2014.

11 Jean Roche, "Exposé introductif", Symposium sur Brasilia, Caravelle. Cahiers du monde hispanique et luso-brésilien № 3, Tolouse, 1964, p. 366. El simposio se desarrolló como parte del coloquio "Los problemas de las Capitales en América Latina", Universidad de Toulouse, febrero de 1964.

12 Juscelino Kubitschek, entrevista en la revista Modulo № 4, Río de Janeiro, mayo de 1956.
} 
(1951-55) y, por supuesto, fue Niemeyer a quien puso al frente del proyecto Brasilia apenas lo lanzó desde la presidencia. Aunque al parecer su intención inicial buscaba asignarle directamente el encargo, el temor de que lo hiciera, más la campaña de otras figuras para que se invitara como proyectista o consultor a Le Corbusier (quien por supuesto ya había ofrecido sus servicios), motivó una intervención del Instituto de Arquitectos do Brasil (IAB) exigiendo un llamado a concurso para profesionales nacionales (arquitectos e ingenieros) y recomendando la elaboración de un plano regional con consideraciones socio-económicas y geográficas. Lo primero se realizó, pero nada semejante a lo segundo: todas las decisiones que se tomaron para el llamado a concurso respondieron a una concepción restringidamente arquitectónica, y en todas ellas se revela la mano del arquitecto estrella de Kubitschek, que como jefe del Departamento de Urbanismo y Arquitectura de la empresa urbanizadora del estado, Novacap, comenzó a proyectar algunas obras importantes ya antes del concurso, integró su jurado y, luego de seleccionado como ganador el plano piloto de Lucio Costa, tuvo la potestad de concebir todos los demás edificios que iban a darle el carácter a la ciudad capital. ${ }^{13}$

La actitud enérgica del IAB fue más allá de las críticas al programa y a la forma de llamado a concurso -lo que obligó a Niemeyer a dejar la vicepresidencia de la entidad-: su participación con un representante en el jurado resultó en una sonada renuncia que denunciaba el tiempo récord en que se había decidido al ganador. Las exigencias del IAB revelan lo consolidados que estaban, ya no sólo entre los arquitectos especializados en urbanismo, sino en el propio corazón profesional de la disciplina, algunos protocolos básicos de la planificación, cuya matriz británica explica el amplio respaldo que recibió el proyecto de plano piloto presentado por el atelier de los hermanos Roberto (tercer premio en el concurso), que se fundamentaba en un programa analítico muy detallado, en la tradición de los surveys de Geddes y Abercrombie, en el polo más antitético imaginable a la apuesta sintética del de Lucio Costa. Por esa misma razón, la influyente revista Hábitat -ya volveremos a ella- que compartía el diagnóstico sobre la necesidad de generar una "mentalidade de planejamento" en Brasil, iba a presentar a la nueva capital como su principal obstáculo: enfatizando que cualquier avance en el tema del planeamiento debía suponer una toma de distancia de lo realizado con la nueva capital, el editorial repetía, como un sonsonete, una sentencia terminante: "Mais deixemos Brasília". ${ }^{14}$

Si eso ocurría en el campo profesional de la arquitectura, "deixemos Brasília" parece ser una frase incluso más apropiada para caracterizar la actitud de la planificación propiamente dicha. Como muestra de ese rasgo a escala latinoamericana, alcanza mencionar el caso de un importante seminario sobre planificación regional y urbana que se realizó en 1972 en Viña del Mar: Brasilia, que no había ocupado el interés de ninguna de las ponencias, fue mencionada en los debates por uno de sus principales animadores, el planificador polaco Antoni Kuklinski, sólo como rémora que era necesario "dejar de lado como un caso especial sin importancia" si se quería abordar una discusión seria sobre "la construcción de ciudades nuevas y eficientes". ${ }^{15}$ Es por eso que la inmensa mayoría de los estudios sobre la planificación desarrollista en Brasil

${ }^{13}$ El programa para el concurso (Edital) se limitaba a lo que la jerga arquitectónica llama la "idea de partido": pedía apenas un "plano piloto" de escala 1:25.000 y una memoria descriptiva, dejando como opcional la entrega de otro tipo de estudios y análisis que respaldaran la propuesta; no se indicaba siquiera la cantidad de población (la cifra de 500.000 habitantes fue un agregado posterior por exigencia del IAB, pero no se dio ninguna argumentación que la justificase), ni se ofrecía un detalle de las necesidades administrativas o políticas para orientar a los concursantes. El Edital puede verse reproducido, junto con parte de la correspondencia entre el IAB y la Novacap, en Milton Braga, $O$ concurso de Brasília, São Paulo, CosacNaify, 2010, pp. 39-44 (el excelente estudio introductorio de Guilherme Wisnik ofrece un análisis pormenorizado de todo el complejo proceso).

14 "Mentalidade de planejamento", Hábitat N 54, São Paulo, mayo-junio 1959, p. 1. La revista se había manifestado inicialmente en contra del concurso y, una vez definido el resultado, puso el énfasis en el voto disidente del miembro del IAB y difundió los proyectos no ganadores: ver Hábitat $\mathrm{N}^{\circ}$ 40-1, São Paulo, marzo-abril de 1957.

${ }^{15}$ Ver ILPES, Planificación regional y urbana en América Latina, México, Siglo XXI Editores, 1974, p. 371. Otro ejemplo, más general: no hay artículos sobre la nueva capital del Brasil en las decenas de números de la Revista Interamericana de Planificación, órgano de la SIAP, desde su inicio en 1967 y durante la década de 1970. 
se dedica al análisis de otra iniciativa del gobierno de Kubitschek, la Operación Nordeste, como se llamó al plan llevado adelante desde la creación de la SUDENE en 1959, y las escasas referencias a Brasilia que aparecen suelen centrarse en sus dramáticos efectos en el presupuesto público y la inflación. El propio Celso Furtado -inspirador y primer director de la SUDENE- iba a otorgarle un lugar poco loable a la nueva capital en sus memorias: su construcción fue para él un proyecto improvisado que introdujo

no que poderia ter sido uma primeira política ordenada de industrialização um formidável potencial de desequilíbrio [...]. Procurei informar-me junto a colaboradores do candidato Kubitschek se havia alguma estimativa do montante de recursos que absorveria a construção de Brasília em tão curto espaço de tempo, mas aparentemente ninguém estava capacitado a responder. A chamada "metassíntese" teria saído da cabeça do candidato pronta, não comportando qualquer modificação, como Palas Atena da cabeça de Júpiter. ${ }^{16}$

En efecto, Kubitschek no había consultado ni al equipo del Banco Nacional de Desarrollo Económico, en cuyos análisis se apoyó para la elaboración del Plan de Metas, ni al del Instituto Superior de Estudios Brasileños (ISEB), el centro creado en 1955 que iba a funcionar como think tank de sus planes desarrollistas, ratificando que para él la nueva capital era un hecho arquitectónico, un factor de impulso simbólico a esos planes, más que una parte estructural de ellos. Uno de los excepcionales casos en que Brasilia sirvió de reflexión para una figura de primera línea en el respaldo técnico-filosófico del presidente, es el de Roland Corbisier, director del ISEB, que en una conferencia puso en vinculación la nueva capital con el proyecto más general de desarrollo. Pero si se analiza su texto, resulta una confirmación de lo dicho por Furtado: la conferencia parece una justificación a posteriori de la decisión, que se sumaba al coro de las argumentaciones partisanas para defender la gestión en el momento en que mayores ataques recibía -y en el tema que más erizaba a la oposición. El argumento de Corbisier ratificaba que "a interiorização da capital" se correspondía con "às exigências do desenvolvimento, da integração econômica e cultural", en la búsqueda de lograr, por primera vez en la historia del Brasil, "a coincidência entre o espaço nacional e o poder nacional" -como si la soledad del Planalto, justamente ese carácter desértico tan criticado por los opositores a la mudanza, fuera lo que podía garantizar una verdadera neutralidad del estado, hasta entonces rehén de las regiones privilegiadas. ${ }^{17}$

Es justamente esa correlación automática, establecida por el discurso oficial, entre integración, desarrollo y creación de la nueva capital, lo que ponían en cuestión los reclamos por la ausencia de planificación, como queda claro en las respuestas mayoritarias que recibía en Toulouse el entusiasmo de Jean Roche:

[Usted] ha mencionado la interiorización: que Brasil tomará posesión de su territorio. Una gran idea [subrayaba irónico el geógrafo alemán Gottfried Pfeifer, cuestionando el argumento histórico]. Una idea bandeirante, tolerable hacia la primera mitad del siglo XIX. ¿Pero hoy? ¿Es posible tomar posesión de un territorio mal desarrollado por medio de la implantación de una gran ciudad? ${ }^{18}$

Vale la pena insistir con el simposio de Toulouse no tanto por la originalidad de las posiciones presentadas, como por su representatividad: allí aparecieron en forma muy sintética las

${ }^{16}$ Celso Furtado, A fantasia organizada [1985], en Obra autobiográfica, São Paulo, Companhia das Letras, 2014, p. 159.

17 Roland Corbisier, "Brasília e o Desenvolvimento Nacional" [1960], en Alberto Xavier y Julio Katinsky (orgs.), Brasília - antología crítica, São Paulo, Cosac Naify, 2012, pp. 73 y 75 respectivamente. El artículo es la reproducción de la última conferencia del ciclo que con el mismo nombre se realizó en el ISEB; se publicó en la revista Módulo N 18 (1960) y salió el mismo año como folleto del ISEB: Roland Corbisier, Brasília e o Desenvolvimento Nacional, Río de Janeiro, ISEB-MEC, 1960. El argumento de la neutralidad en la visión de los defensores de la mudanza ha sido trabajado por Frederico de Holanda, O espaço de exceção, Brasilia, Editora Universidade de Brasília, 2012.

18 "Remarques de M. Pfeifer", Symposium sur Brasilia, Caravelle, op. cit., p. 387. 
modalidades con que se iba a evaluar Brasilia durante todo nuestro período en los ámbitos especializados: de un lado, el optimismo desarrollista de Roche, que ya en 1964 comenzaba a ser minoritario -y hay que tener en cuenta que cuando se hizo el simposio todavía no había ocurrido el golpe de estado, cuyas escenas de quiebre institucional y represión iban a ser leídas por muchos en esos ámbitos como un fin de ciclo para Brasil-; del otro lado, los dos argumentos centrales con que se iba a contrastar, uno geográfico-territorial y el otro socioeconómico.

El geográfico está expresado con claridad en la intervención de Pfeifer, pero el brasileñista Pierre Monbeig lo compendió en una fórmula muy gráfica: suponer que esa "nueva epopeya bandeirante" por conquistar el vacío interior podía ser la palanca para desarrollar el país realmente existente, dijo, mostraba que sus promotores eran "víctimas de la magia de los espacios". ${ }^{19}$ Nadie dudaba de que el nuevo mapa de rutas que mostraba la conexión radial desde Brasilia al interior del Brasil, con las intrépidas obras para unir la capital con Belem y con Fortaleza como expresión material de la gesta implicada en su concreción, favorecía un nuevo nivel de penetración territorial y comunicación interna, pero la pregunta clave era si se necesitaba crear artificialmente una nueva gran ciudad en el corazón de esa red. ¿No era un regreso a las visiones pre-científicas del siglo XVIII, con su aspiración de regularizar territorio y administración, confundiendo geografía con geometría (como una versión racionalista de la "magia de los espacios")?

El argumento económico-social fue bien expresado en Toulouse por la intervención de Milton Santos, con el tono que ya iba a ser característico en los abordajes críticos de la nueva capital por la geografía y la sociología urbanas. Básicamente, Santos puso frente a frente la "vontade criadora" de una "cidade artificial" y la realidad del subdesarrollo del país: si la nueva capital se anunciaba como solución para "os famosos desequilibrios regionais", su implantación no hizo más que reproducir en su interior el hecho "persistente" que es "o sub-desenvolvimento brasileiro", expresado en los miles de "candangos" que fueron a construir la ciudad desde el Nordeste y se quedaron a vivir allí, no sin que mediaran intensas y dramáticas luchas sociales -ya que el plano piloto no los contemplaba ni los incluyó-, que resultaron en las llamadas "ciudades satélites". De tal modo, para Santos el "dualismo" característico del Brasil se introdujo como hecho originario de la flamante capital que supuestamente venía a superarlo; por eso, a cuatro años de inaugurada, Brasilia ya podía ser equiparada a cualquier otra capital latinoamericana. ${ }^{20}$

Subrayé el término "artificial", que aparece en todas las intervenciones con claras inflexiones peyorativas, porque es un tópico del pensamiento urbano, marcado a fuego por la antropogeografía francesa que, con el modelo ideal de las ciudades medievales, estableció ya en el siglo XIX uno de los patrones más estables y potentes de definición de la normalidad urbana: de acuerdo a ella, una ciudad es el emergente natural de las funciones económicas y sociales de una región, el nodo que se forma allí donde esas funciones se intensifican. ${ }^{21}$ Es decir, todo lo contrario de Brasilia. Como ya había señalado en 1960 Bruno Zevi, una de las figuras del pensamiento arquitectónico internacional que se opuso con mayor vehemencia a la nueva capital, una ciudad "verdadera" debe ser construida "por un impulso sano, que no sea meramente político"; así, el "carácter parasitario" de Brasilia está inscripto en su origen, ya que las ciudades "sanas" nacen "no por decretos gubernamentales, ni por actos de fuerza, ni con artificios". ${ }^{22}$ El sistema de equivalencias es inequívoco y traslada el juicio negativo desde la metáfora orgánica a la vida política: ciudad natural (resultado sano de la dinámica socioeconómica de su región), versus ciudad artificial (parásita, producto de la decisión política que la implanta desde afuera). Y da una de las razones para que la decisión de crear Brasilia

\footnotetext{
${ }^{19}$ Symposium sur Brasilia, op. cit., p. 393.

${ }^{20}$ Milton Santos, "Brasília, a nova capital brasileira", Symposium sur Brasilia, op. cit., pp. 371-73.

${ }^{21}$ Un ejemplo claro dentro de esa tradición es la obra (muy influyente en el pensamiento urbano) de Henri Pirenne, Las ciudades de la Edad Media (1927), Madrid, Alianza Editorial, 1972.

22 Bruno Zevi, "Inchiesta su Brasilia. Sei [questione] sulla nuova capitale sudamericana", L'architettura. Cronache e Storia № 51, Milán, enero de 1960, pp. 609 y 613.
} 
haya dividido al país en uno de los debates más intensos que se recuerden: el fundamento exclusivamente político de Brasilia hizo que empalmaran las voces más técnicas y especializadas con el vasto conjunto de quienes, apoyados sea en disidencias programáticas 0 en cálculos de oportunidad, Ilevaron adelante una oposición furibunda a Kubitschek.

Lo que desde el punto de vista de la épica desarrollista podía constituir un valor, la "impulsión creadora" por una transformación voluntarista del territorio, para el pensamiento planificador y urbano se convertía en un hecho monstruoso -es decir, contrario al orden de la naturaleza-, confirmando (en el caso de los críticos extranjeros) la imagen ya consolidada de los países latinoamericanos como sitios de autocracias extravagantes, capaces, por ejemplo, de construir una ciudad radiante en medio de la nada. Así, el monumentalismo programático de Brasilia fue interpretado por muchos como la encarnación del autoritarismo, tanto por sus efectos espaciales -la concreción espectral de una ciudad kafkiana-, como por su significado más amplio de expresión urbano-arquitectónica de las necesidades políticas de un régimen. Y si sorprende cuando Zevi, por ejemplo, se vio en la obligación de aclararle a su público italiano, luego de esgrimir todos estos argumentos en 1960, que Kubitschek era, con todo, un presidente democrático, conviene recordar que también un brasileño como Joaquim Guedes pudo sostener en 1974 que el monumentalismo de Brasilia, como profecía autocumplida, era la prueba de que la dictadura brasileña había comenzado ya con el presidente desarrollista. ${ }^{23} \mathrm{En}$ ese contexto, la proeza de levantarla en tres años debiendo transportar todos los materiales de construcción por avión, lejos de llamar a admirado asombro, respaldaba del modo más contundente las denuncias sobre el carácter "faraónico" de una empresa que, así presentada, sólo cabía explicar en la "embriaguês [de certos políticos] de passar à História". ${ }^{24}$

\section{El huevo de Colón}

Si bien conviene no confundir las razones de los especialistas que se oponían a la nueva capital con las impugnaciones que promovía el erizado clima de enfrentamiento político, ya que se corre el riesgo de adelgazar un debate de múltiples y complejas lógicas, es evidente que hay un punto en el que confluyen hasta superponerse: la denuncia de la primacía de la voluntad política. Por ello, es muy interesante analizar los argumentos de los dos autores con cuyas citas iniciamos el artículo, Wilheim y Pedrosa, dos figuras de perfiles muy contrastantes, uno arquitecto-urbanista y el otro crítico de arte e intelectual de izquierda, porque las reservas técnicas e ideológicas que ambos tenían sobre el proyecto no les impidieron una comprensión empática y enfática, distinguiéndose así tanto del coro oficialista de los defensores partisanos como del de los detractores a ultranza, y abriendo un abanico de cuestiones de gran significación para nuestro enfoque.

\footnotetext{
${ }^{23}$ El propio Guedes recordaba autocríticamente esa afirmación en "Por uma nova cidade", $A U$ № 2, São Paulo, abril 1985, p. 69. "Profecía autocumplida" la llamó también Zevi apenas ocurrido el golpe del 64. Por supuesto, también hubo voces que buscaron complejizar la cuestión, como la de Leonardo Benevolo, que habiendo escrito críticamente sobre Brasilia en 1960, en una edición posterior del mismo texto introdujo un párrafo advirtiendo que "el cambio violento de dirección política" (el golpe de 1964) ha "falseado" la polémica sobre las direcciones y los resultados del proyecto; ver Storia della architettura moderna, Roma, Laterza, 1975 (sexta edición), pág. 843.

24 J.M.A [J. de Almeida Mattos], Brasil Arquitetura Contemporânea № 10, Río de Janeiro, 1957, p. 1. Almeida Mattos había publicado en el número anterior un detallado análisis que buscó demoler la propuesta de mudanza de la capital en términos políticos y geográficos: ver "A mirabolante nova capital brasileira”, Brasil Arquitetura Contemporânea № 9, Río de Janeiro, 1957, pp. 3-20. La propia personalidad de Kubitschek alentaba muchas de esas acusaciones: incluso Furtado, colaborador cercano que nunca iba a dejar de destacar sus dotes de gran estadista visionario, al mismo tiempo registraba que JK "era o mais sensível a ver seu nome 'imortalizado' numa placa celebradora”, cuánto más en toda una ciudad; en A fantasia desfeita [1989], segunda parte de la Obra autobiográfica, op. cit., p. 364.
} 


\section{Una empresa para la forma arquitectónica}

Comencemos por Jorge Wilheim, que fue uno de los 26 participantes que compitieron en el concurso del plano piloto. Egresado como arquitecto en 1952 de la Universidad Presbítera Mackenzie -una de las escuelas tradicionales de São Paulo-, su interés por el urbanismo siguió la lógica bastante espontánea de su generación, marcada por la articulación "natural" entre arquitectura y urbanismo establecida por el ideario modernista, del que había sido un introductor decidido desde sus años de estudiante. ${ }^{25}$ En este sentido, arma familia con muchos de los urbanistas que salían por entonces de las facultades de arquitectura: sin demasiado entrenamiento académico especializado, pero con mucha experiencia ganada en el terreno y lecturas abundantes de economía, sociología y geografía, de las que hacía un uso ecléctico y, sobre todo, cuyos datos "duros" traducía a los rasgos físicos del paisaje territorial y a las necesidades formales del plan urbano, con el énfasis puesto en la dinámica proyectual.

Su presentación en el concurso del plano piloto para Brasilia estuvo respaldada por uno de los análisis socio-económicos y geográficos más exhaustivos, realizados por un equipo formado por paisajistas, economistas, sociólogos y agrónomos que contribuyeron con un estudio sobre la inserción regional de la futura capital. Como muchos de los proyectos presentados, uno de los rasgos que más lo diferenciaron del de Costa es que partió del supuesto de una mudanza por etapas y, en consecuencia, propuso un "crecimiento orgánico" para su ciudad: una serie de células autosuficientes, dependiente cada una de las funciones administrativas que se irían asentando en la nueva capital de a poco, dando el ritmo de una construcción célula a célula a lo largo de un plazo más o menos prolongado. Lo generalizada de esta decisión etapista entre los concursantes muestra que respondía a un diagnóstico compartido sobre la complejidad de la mudanza de todas las funciones directivas del país a una nueva ciudad a cientos de kilómetros de cualquier centro poblado, pero no contemplaba la determinación política de Kubitschek de hacerlo a marcha forzada durante su mandato (¡cincuenta años en cinco!) y la necesidad, por tanto, de disponer de una imagen urbana global ya completa a la hora de inaugurarla. Esa fue la decisión del proyecto de Costa que para Wilheim lo convirtió en "el huevo de Colón", la única respuesta acertada: "A cidade que se constrói tem toda a força de persuasão de uma realidade; [...] ninguém cogita de uma Brasília morfològicamente diversa". ${ }^{26}$

Así escribía en 1960, en un artículo que integró un número especial de la revista Acrópole dedicado a la inauguración de la nueva capital, en el que Wilheim tuvo a su cargo el análisis global de los antecedentes geográfico-territoriales y urbanos del concurso. Ahora bien, si el análisis regional y socio-habitacional le hacía coincidir con el extendido diagnóstico sobre el carácter "artificial" de Brasilia, su juicio fue menos categórico porque, sin dejar de compartir los presupuestos negativos del pensamiento urbano sobre el tema, su pragmatismo le permitió mantener abierta una ambivalencia entre las convicciones técnicas y las "razones políticas", llevándolo a admitir la importancia de estas últimas en un doble sentido: instrumental, porque reconocía que sin esa "brusca decisão, o investimento maciço, a manutenção de um clima fervilhante de construção rápida a todo custo e a prazo corto", la nueva capital no se hubiera realizado nunca; y sustancial, porque asumía la necesidad de su realización por sus consecuencias no sólo económicas, sino también "subjetivas", en un efecto de "arrastre" como "fuerza catalizadora" para el conjunto de las dimensiones sociales del Brasil. ${ }^{27}$ En ese marco, apostando todo o nada a una forma urbana, la propuesta de Costa fue para Wilheim la única en advertir la primacía de lo político implícita en el concurso. ${ }^{28}$

\footnotetext{
${ }^{25}$ Ver Angélica Tanus Benatti Alvim, Eunice Helena Sguizzardi Abascal y Eduardo Castedo Abrunhosa (orgs.), Arquitetura Mackenzie 100 anos - FAU-Mackenzie 70 anos: pionerismo e atualidade, São Paulo, Editora Mackenzie, 2017 (ed. online), p. 128.

26 Jorge Wilheim, "Brasília 1960. Uma interpretação", Acrópole 256/257, São Paulo, 1960, p. 31.

27 Jorge Wilhelm, "Brasília 1960. Uma interpretação", ibid, pp. 36, 31 y 28 respectivamente.

28 Para Wilheim, Costa había comprendido que "os fatôres sócio-econômicos determinantes" que desvelaron a los concursantes con mayores ambiciones urbanísticas, no modificarían "o caráter e a forma resultante dum gesto arbitrário: uma capital implantada, tôda pronta, concebida como uma unidade, expressando claramente seu caráter político"; Ibid, p. 36.
} 
Pero en el libro de 1969 que citamos en el acápite, Wilheim fue todavía más allá, permitiéndonos entender la extrañeza de la mirada planificadora ante Brasilia. El libro proponía un diagnóstico de la ciudad subdesarrollada que cuestionaba las bases teóricas del urbanismo que se habían formulado teniendo como modelo las ciudades desarrolladas; a eso seguía la definición de una estrategia desarrollista apropiada y, finalmente, Wilheim pasaba revista a varios ejemplos de sus proyectos como planificador, usando cada uno como caso de una problemática específica. Un libro muy a tono con el pensamiento urbano de la época, pero que sobre el final produce un salto de registro revelador: el autor advierte que hasta allí no le había dado lugar a Brasilia, cosa que no habría sido sorprendente, como vimos, en la mayor parte de la literatura sobre la planificación latinoamericana del período; pero el arquitecto que hay en Wilheim decide, en cambio, que un libro de urbanismo brasileño no puede eludir el desafío. La cuestión es cómo hacerlo, porque si el problema del libro era tratar de entender "a adequação metodológica da urbanística em país subdesenvolvido", no le resultaba sencillo incorporar una ciudad como Brasilia que "discorda, aparentemente, de todos os conceitos" (tal cual los enumeraba en la cita del acápite: "sem plano integrado, sem análise sócio-econômica", etc., etc.), pero sin embargo deu certo: "a cidade existe e se parece bastante com a admirável descrição, mais literária do que gráfica", que dio Lucio Costa. ${ }^{29}$ Para explicarlo, Wilheim pone las fallas de su propio proyecto para el concurso como ejemplo aleccionador: él había elaborado "talvez o mais completo diagnóstico da região", pero no pudo "lançar a ponte entre esse diagnóstico e o partido da capital nova, seu desenho", una vacilación que "existe de forma multiplicada à medida que o grupo profissional aumenta"; así, "não é de estranhar que muito plano elaborado por firma grande apresente volumosa pesquisa e diagnóstico, mas se caracterize pela pobreza da proposta, medo de arriscar, hesitação e contemporização em resolver problemas". Y es que "parece verdade que entre criatividade e número de participantes, exista uma razão inversa". ${ }^{30}$ Luego de tamaño ejercicio de honestidad intelectual, el artículo retornaba a las certidumbres de la planificación, concluyendo que la excepcionalidad política de Brasilia impedía "elevar o método de trabalho que precedeu [sua implantação] ao status de modelo metodológico". ${ }^{31}$ Pero su exposición de ese "caso anómalo" no dejaba de echar una sombra de sospecha sobre aquellas aparentes constantes en las que había propuesto apoyarse, con tanta confianza en las bases científicas de su racionalidad.

\section{Una empresa para la utopía artística}

Mario Pedrosa utilizó un poco antes que Wilheim la metáfora del "huevo de Colón" para definir el hallazgo de Lucio Costa: un plano con tal claridad de partido que convirtió una empresa dudosa en la posibilidad de una utopía colectiva. ${ }^{32}$ Pero comencemos diciendo que esa interpretación partió de un lugar doblemente diferente del de Wilheim: desde una posición de izquierda comprometida y desde los presupuestos del arte y la cultura, frente al pragmatismo y al enfoque especializado del urbanista. Por ello, la superación de sus reservas iniciales y los argumentos con que la defendió describen un recorrido muy distinto, tanto como lo fue el lugar de enunciación de cada uno para la época de la construcción de Brasilia: mientras Wilheim, muy joven, hacía sus primeras apariciones públicas en el mundo de la arquitectura, Pedrosa, mucho mayor (nacido en 1900 en Pernambuco, en 1960 le doblaba la edad), era ya un referente fundamental de la crítica de arte y de la vida política y cultural.

Por esa misma razón, hay muy buenos estudios sobre él, tanto por su importancia en la vida política como en la escena del arte: en la primera, desde que editó en Rio de Janeiro la revista Vanguarda Socialista (1945-1948), con la que promovió un debate teórico dentro del marxismo y una alternativa política socialista (antistalinista y post-trotskista) de fuerte impacto en el medio

\footnotetext{
29 Jorge Wilheim, "Brasília 1969: um comentário indispensável", en Urbanismo no subdesenvolvimento, op. cit. p. 384.

30 lbid, pp. 385.

31 Ibid, p. 391.

32 "Reflexões em torno da nova capital", Brasil - Arquitetura contemporânea № 10, Rio de Janeiro, 1957, reproducido en Mario Pedrosa, Dos murais de Portinari aos espaços de Brasília, op. cit., p. 309.
} 
intelectual; en la segunda, su apuesta decidida por el arte concreto en los años 50 contra las viejas glorias del modernismo brasileño lo volvió una figura ineludible, como crítico académico y periodístico y como gestor en museos y bienales. ${ }^{33}$ Fue su adhesión al concretismo lo que lo llevó a la arquitectura, en el momento en que ésta colocaba a Brasil en la primera plana mundial, confirmando las aspiraciones del crítico de una conexión local/internacional de alta productividad mutua. La arquitectura fue para él el hecho estético total -"síntesis de las artes", según la expresión de uso en la época-, en tanto condensaba en una forma espacial la ligazón más compleja y completa entre arte y sociedad. Y si así era la arquitectura, tanto más la ciudad, "obra de arte colectiva", como le gustaba decir citando a Lewis Mumford, razón de más para que haya dedicado una atención destacada a Brasilia, sobre lo que también hay algunos textos críticos indispensables en los que me apoyo. ${ }^{34}$

Sin embargo, creo que no han sido examinados dos asuntos que hacen a nuestro enfoque, permitiendo ver aspectos interesantes de la relación de Brasilia con la planificación: la importancia de entender lo abrupto e imprevisible de la adhesión de Pedrosa al proyecto de la nueva capital, y en relación con ello, su forma de razonar partiendo de coincidencias programáticas con las posiciones de quienes más vehementemente se opusieron.

Su adhesión era completamente improbable por razones tanto políticas como estéticas. En primerísimo lugar, por las reservas de todo tipo que le producía el tándem KubitschekNiemeyer, protagonista inevitable en cualquier evaluación de la empresa de mudanza. En 1953, en un cuadro comprehensivo de la arquitectura moderna brasileña que ofreció como presentación de una exposición en París, había definido a Pampulha, aquel emprendimiento inaugural del tándem, como una exhibición de "formas gratuitas", atribuible a una combinación del "temperamento barroco" del arquitecto con el "programa de capricho e de luxo do pequeno ditador local". ${ }^{35}$ Respecto de la opinión sobre Kubitschek, hay que aclarar que si bien su gestión como Prefecto de Belo Horizonte, cuando encarga Pampulha, se enmarca en la dictadura del Estado Novo de Vargas, en el momento en que Pedrosa emitía su juicio, en cambio, el "pequeno ditador local" ya era gobernador de Minas Gerais elegido democráticamente, así como iba a ser presidente democrático cuando lanzara Brasilia, sin que el escepticismo del crítico sobre su figura disminuyera: "A Brasília de Lúcio Costa é uma bela utopía -escribió después del concurso-, mas terá ela algo que ver com a Brasília que Juscelino Kubitschek quer edificar? [...] uma nova Pampulha, isto é, uma obra, embora bela, mas suntuosa e prefeitural". ${ }^{36}$

Respecto de Niemeyer, sus posiciones fueron más ambiguas y contradictorias: ese "verdadeiro playboy da arquitetura moderna ocidental" -como lo llamó en uno de sus comentarios- tenía elementos destacables, pero no cabe duda de que su creatividad individualista y desbocada, su forma de convertir los principios modernistas en "estilo" y su tendencia al "puro formalismo" no podían entusiasmar a Pedrosa. La adhesión al programa severo del arte concreto suponía darle centralidad en la arquitectura a la racionalidad (y la responsabilidad) técnico-social de la labor constructiva, en las antípodas de las inclinaciones "caprichosas" de Niemeyer. Y hay que destacar la vinculación estrecha de Pedrosa al círculo de la revista Hábitat, también comprometida con el impulso al arte concreto en la figura de su principal mentora, Lina Bo Bardi. A lo largo de 1956, la revista publicó una serie de artículos proponiendo un canon de la arquitectura moderna brasileña que, en pleno apogeo de la figura de Niemeyer, lo excluía. El autor era el crítico Geraldo Ferraz, muy próximo a Pedrosa en sus opiniones estéticas y

\footnotetext{
${ }^{33}$ Ver José Castilho Marques Neto (org.), Mario Pedrosa e o Brasil, São Paulo, Editora Fundacao Perseu Abramo, 2001, en cuyos artículos pueden seguirse las diferentes facetas de su actividad.

${ }^{34}$ Para la obra de Pedrosa como crítico de la arquitectura y la ciudad, destaco los textos de Otilia Arantes, Mário Pedrosa: Itinerário crítico, São Paulo, Editora Página Aberta, 1991; y Guilherme Wisnik, "Apresentação", en Arquitetura: ensaios críticos: Mário Pedrosa, São Paulo, Cosac Naify, 2015.

35 "A arquitetura moderna no Brasil", conferencia publicada en L'Architecture d'Aujurd'Hui, diciembre de 1953, reproducida en Mario Pedrosa, Dos murais de Portinari aos espaços de Brasília, op. cit., p. 259.

36 "Reflexões em torno da nova capital" (1957), reproducido en Ibid, pp. 307 y 309.
} 
también políticas (ambos provenían del trotskismo), lo que agrega un nuevo frente de desconfianza ante el comunista Niemeyer. ${ }^{37}$

Recién en 1958, gracias al famoso "Depoimento" autocrítico en el que Niemeyer se arrepentía de su "tendência excessiva à originalidade" y prometía buscar desde ese momento "a simplificação da forma plástica e o seu equilíbrio com os problemas funcionais e construtivos" arrepentimiento que Pedrosa vio como el "despertar da [sua] consciência social"-, se decidió a colocarlo entre los "artistas verdadeiramente grandes"; pero lo interesante es que, para el crítico, esa transformación del arquitecto pudo ocurrir gracias a la experiencia de Brasilia: fue esa "formidável e nobre missão" lo que lo habría llevado a producir la "síntese do político e do social com o estético-profissional". ${ }^{8}$ Es decir que el entusiasmo de Pedrosa por la nueva capital no sólo era poco previsible, sino que fue tan exultante, que llegó a concebir esa creación del político y el arquitecto como una redención para ambos: Niemeyer encontró allí su "nobre missão", mientras que "o único traço não medíocre do atual presidente da República está precisamente nessa prioridade que pretende dar a Brasília" ${ }^{39}$

Todo indica que tal epifanía la recibió Pedrosa directamente del proyecto de Lucio Costa, porque hasta entonces el "imediatismo" de la propuesta de mudanza, su "caráter obscuro e híbrido", le hacían temer "que monstro de 'modernismos' e 'nacionalismos' não poderá resultar de toda essa barafunda". ${ }^{40} \mathrm{Y}$ por ese camino anticipó la respuesta de las figuras más representativas del movimiento concretista ante la Brasilia de Costa y Niemeyer, en una adhesión que no puede explicarse en el programa estético específico, sino en el lugar que comenzó a ocupar la nueva capital en el frente de opinión interno. En efecto, no ya la criticada exuberancia de Niemeyer, sino tampoco la sobria apuesta a la "gran forma" del plano de Costa podían sintonizar con las afinidades estéticas de los concretistas, cuyo uso de la abstracción geométrica buscaba borrar -como señaló Gonzalo Aguilar- "la individualidad y la expresión, consideradas ambas residuos románticos". ${ }^{41}$ En cambio, a medida que su construcción avanzaba y ciertas imágenes -como la del plano-cruz de Costa o la de los arcos invertidos de la columnata del palacio de Alvorada de Niemeyer- demostraban su potencia icónica en el imaginario social, Brasilia ocupó su lugar, con una velocidad digna de las aspiraciones de Kubitschek, entre los hechos clave de autoafirmación cultural de la modernidad brasileña, como la bossa nova, que surgió exactamente para la misma época y se impuso a igual velocidad: una figura poderosísima de una cultura nacional-popular que se veía proyectada internacionalmente. $^{42}$ Ese fue el triunfo indiscutido de Brasilia: mientras que su suerte crítica en la escena internacional mostró grandes oscilaciones en el tiempo, no cabe ninguna duda de que se instaló casi desde el comienzo como un hecho definitivo de la cultura brasileña. Para Wilheim esa potencia icónica mostraba la capacidad significante de la arquitectura en oposición a la aridez tecnocrática de la planificación; para Pedrosa, se trató del componente utópico que anida en el arte:

\footnotetext{
${ }^{37}$ La serie de notas de Ferraz estuvo compuesta por semblanzas biográficas de Warchawchik, Reidy, Levi, Roberto, Costa y Burle Marx; fue publicada entre marzo y noviembre de 1956. Conviene aclarar que no obstante las comunes reservas frente a Niemeyer, las versiones historiográficas de Ferraz y Pedrosa tienen importantes diferencias, en especial respecto de la valoración de Lucio Costa.

${ }_{38}$ Mario Pedrosa, "O depoimento de Oscar Niemeyer" (1958), reproducido en Dos murais de Portinari aos espaços de Brasília, op. cit., pp. 293-295.

39 Mario Pedrosa, "Nuvens sobre Brasília", artículo del 13 de junio de 1958 reproducido en Ibid, p. 339.

40 Mario Pedrosa, "Reflexões em torno da nova capital" (1957), reproducido en ibid, pp. 306 y 309.

${ }^{41}$ Ver Gonzalo Aguilar, "El laberinto transparente. La poesía concreta brasileña en la ciudad", Block $N^{\circ} 4$, Buenos Aires, UTDT, diciembre de 1999, p. 89. La actitud inicial de la revista Hábitat es muy clara respecto de las afinidades concretistas: su preferencia entre los planos concursados fue para el de Rino Levi, cuyas abstractas y livianas estructuras laminares calificó como "la ciudad del siglo XXI".

42 Siguiendo la temprana revelación de Pedrosa, ya en 1958 el grupo de poetas concretos titulaba su manifiesto inaugural "Plano piloto" en directa alusión al proyecto de Costa, considerándolo un "manifiesto concreto" y una guía de acción para su propio arte: ver Augusto de Campos, Décio Pignatari y Haroldo de Campos, "Plano-pilôto para poesia concreta", Noigandres № 4, São Paulo, 1958.
} 
Lúcio deu à vaga ideia de Brasília (horrível nome sintético!) a concepção básica que lhe faltava, sua estrutura física, sua forma plástica, sua primeira imagem visual. E eliminou tudo o mais como temporão. Todo mundo viu, então. Todos, a partir dos entendidos [se refiere al jurado del concurso], entenderam, afinal, o problema, e compreenderam a solução proposta. [...] [E] ao compreender a sua ideia, por ela se entusiasmaram. Ergueu-se, aqui, um pensamento soberano para dominar a matéria informe, e o fez, em ênfase, com uma gravidade doce. Os colegas concorrentes de Lúcio, alguns deles eminentes na sua especialidade, perderam-se nos pormenores. Partiram das partes para o todo, enquanto ele fez a démarche inversa. É que nele o pensador venceu o técnico. Visionário, Colombo descobriu a América fundado numa dedução lógica, a partir de redondeza da Terra. A América foi, por isso, um produto da fé na razão inteligente do homem. E não em vão foi ela a sede das primeiras utopias pós-renascentistas. Brasília foi, enfim, definida por uma ideia. Transformou-se, portanto, numa utopia. Ora, quem diz utopia, diz arte, diz vontade criadora. A partir daí, todos podemos trabalhar por ela. ${ }^{43}$

Con esos argumentos como base, Pedrosa se dedicó a una intensa campaña en favor de la nueva capital que tuvo como momento culminante el célebre congreso de la Asociación Internacional de Críticos de Arte que se realizó en septiembre de 1959 en Brasilia, Río de Janeiro y São Paulo, donde el tema fue abordado frente a decenas de figuras destacadas de todo el mundo; por intermedio de Pedrosa, entonces vicepresidente de la Asociación, el congreso se inauguró en la nueva capital que se construía a toda máquina, dándole una repercusión a tono con la campaña de propaganda que venía haciendo el gobierno -el mismo Kubitschek presidió la primera sesión, a la que en indisimulado tributo se había titulado "Cidade nova: síntese de artes". ${ }^{44}$

Pues bien, aquí aparece el segundo rasgo que mencioné, por el cual conviene revisar los argumentos de Pedrosa: el modo mismo en que él construyó su defensa de Brasilia a partir de coincidencias programáticas con las posiciones de quienes la rechazaban más categóricamente. Esa forma de argumentar venía desde el mismo inicio de su actividad como crítico de la arquitectura, que comenzó en 1953, el año en que, luego de una década de creciente notoriedad internacional, aparecieron las primeras voces en poner reparos al "estilo brasileño". El toque de diana para ese cambio fue el célebre affaire Max Bill: en una visita que se esperaba consagratoria, el maestro concretista suizo criticó, en declaraciones que provocaron escándalo, la tendencia brasileña a subvertir los rasgos para él sustanciales de la arquitectura moderna -racionalidad, adecuación técnica y función social. ${ }^{45}$ La revista Hábitat se puso del lado de Bill, con quien Pedrosa tenía además una intensa relación tanto personal como filosófica, a la que debía en buena medida su propio interés por la arquitectura, poniendo en primer plano los "ideais democráticos e sociais" y los "princípios racionais e funcionalistas". ${ }^{46}$

\footnotetext{
${ }^{43}$ Mario Pedrosa, "Reflexões em torno da nova capital" (1957), op. cit., pp. 309-310.

44 El congreso sesionó en las tres ciudades del 17 al 25 de septiembre de 1959. Fue un congreso excepcional, fuera del calendario establecido de la AICA, y el primero en el continente americano. Entre otros, participaron Giulio Carlo Argan, Bruno Zevi, André Chastel, Meyer Schapiro, Douglas Haskell y los argentinos Tomás Maldonado y Jorge Romero Brest. Las Actas han sido publicadas: Maria da Silveira Lobo y Roberto Segre (orgs.), Congresso Internacional de Críticos de Arte. Cidade nova: síntese de artes, Rio de Janeiro, UFRJ-FAU, 2009.

${ }^{45}$ La consagración internacional de la arquitectura brasileña se produjo con la muestra Brazil Builds, en el MOMA de Nueva York en 1943: ver Carlos Martins, “'Hay algo de irracional...' Apuntes sobre la historiografía de la arquitectura brasileña", Block 4, Buenos Aires, UTDT, diciembre de 1999. El affaire Bill abrió, diez años después, el ciclo opuesto, con un hito inmediato en el "Report on Brazil" organizado por The Achitectural Review en 1954; ver Guilherme Wisnik, "Modernidade congênita", en E. Andreoli y A. Forty, Arquitetura moderna brasileira, Londres/Nueva York, Phaidon, 2004

${ }^{46}$ Las citas entrecomilladas provienen del texto de Mario Pedrosa, "A arquitetura moderna no Brasil", op. cit., p. 259. Es importante resaltar que, después de sus declaraciones escandalosas, Bill fue excluido del jurado de la II Bienal de Arquitectura de Brasil, mientras que permaneció en el de la II Bienal de Arte que comenzó a fines del mismo 1953, con organización de Pedrosa, quien mantuvo inalterada su fuerte relación con el suizo: ver Ana Luiza Nobre, Fios cortantes. Projeto e produto, arquitetura e design no Rio de Janeiro, tesis de doctorado, Departamento de História, PUC-Río, 2008, p. 44.
} 
No corresponde detallar aquí el modo en que Pedrosa consiguió en sus primeros textos arribar desde esos acuerdos programáticos con Bill a una inteligente defensa de la arquitectura moderna brasileña en su versión carioca; alcanza con señalar la analogía de los procedimientos con los que veremos para el caso de su defensa de Brasilia: argumentos que compartían las definiciones teóricas de fondo con los antagonistas, pero lograban situar empáticamente los hechos brasileños en el mismo marco conceptual que justificaba su rechazo. $^{47}$

Lo cierto es que gracias a esos compromisos, en unos pocos años, desde la epifanía de 1957 y hasta los debates del Congreso de la AICA en 1959, Pedrosa llegó a proponer algunas interpretaciones que significaron un aporte diferencial frente al pensamiento urbano del período, mostrando que la extrañeza de Brasilia tuvo sus efectos en varios planos. Nos vamos a detener en dos de esas interpretaciones: una refiere al rol específico de Brasilia en el Brasil, y la otra, a una más genérica condición americana.

Pedrosa modifica la interpretación más generalizada que, como vimos, colocaba la implantación de la nueva capital, sea para celebrarla o criticarla, en el curso de la épica bandeirante; para él, en cambio, ese "frente de colonização" paulista, en su "marcha frenética em direção ao Oeste", abusando de las técnicas siempre "devastadoras" del pionero, había sumido al país desarrollado en una "inestabilidad fundamental", impidiendo el surgimiento de una "mentalidade regional" (en el sentido de Mumford, agregaba: "a forma vernácula complexa"). Contra ese movimiento histórico desde el sur, Brasilia es presentada por Pedrosa como un "núcleo central de colonização" que viene a "atacar de flanco a frente dos pioneiros e dos plantadores" paulistas, creando "novas tensões na margem das fronteiras interiores". Su función es la de punto de encuentro de las influencias paulistas y bahianas, contrapesando la finalidad estrictamente económica, capitalista, del frente colonizador, por medio de "uma velha ideia, política", que producirá "uma remodelação geográfica, social e cultural do país inteiro", acelerando, por medio de la planificación, el fin de la marcha pionera y el surgimiento de verdaderas regiones:

A tarefa das novas gerações brasileiras está, pois, fixada: edificar do nada a Capital, que tem o plano mais belo e mais audacioso, e, simultaneamente, e de maneira tão artificial, criar, da terra bruta e pobre, a sua região; o objetivo do plano é definir a forma vernácula complexa da região. ${ }^{48}$

Tomando al pie de la letra la tesis provocativa que había presentado Costa en la memoria del plano piloto ("a concepção urbanística da cidade [...] não será uma decorrência do planejamento regional, mas a causa dele" [página 2 del Relatório]), Pedrosa presentaba la ausencia de regionalismo -blanco principal de los analistas más severos del concurso- como una carencia del país bandeirante (paulista) que Brasilia venía a trastocar. Así, discutía también la idea oficialista del lugar "neutral" para la capital (ergo, para el estado): el Planalto donde se instalaba Brasilia no era neutro; para Pedrosa, traía a escena al país que había quedado afuera "do avanço da especulação pioneira", con su "submissão demasiadamente imediata ao mercado dos preços internacionais" (una crítica por izquierda al desarrollismo aperturista de Kubitschek). De tal modo, trazaba una línea divisoria entre el desarrollismo de la política oficial y la planificación regionalista (el horizonte del humanismo mumfordiano que Brasilia abría como expectativa), como quien traza una línea entre el presente (pasado) y el futuro.

Se trata de un razonamiento curioso, porque para llegar a él Pedrosa apoyaba todo su análisis de ese Brasil presente (pasado) en Pionniers et planteurs de l'État de São Paulo, el importante

\footnotetext{
${ }^{47}$ Con propiedad, Otilia Arantes explicó algunas de las contradicciones de Pedrosa definiéndolo como "un intelectual brasileño fiel a la tradición culturalista de interpretación y acomodación de nuestras singularidades"; Mário Pedrosa: itinerário crítico, op. cit., p. 92.

${ }^{48}$ Mario Pedrosa, "Brasília, a cidade nova", comunicación presentada en el Congreso Internacional de Críticos, Brasilia, septiembre de 1959, reproducido en ibid, p. 352. Los entrecomillados anteriores y posteriores a esta cita provienen del mismo texto, pp. 345-353.
} 
libro publicado en 1952 por Pierre Monbeig, quien, como vimos, iba a ser muy escéptico sobre las posibilidades de Brasilia para transformar aquella situación que ocupaba el centro de su análisis. Pedrosa tomaba el análisis del geógrafo pero, sin más fundamento que su profesión de fe, presentaba a Brasilia como un deus ex machina que permitía superar el pionerismo y dar el primer paso para la emergencia de la dinámica regional -esa dinámica que, según Monbeig, aquel pionerismo habría impedido. Este razonamiento por inversión me interesa especialmente, porque es una operación habitual en la cultura intelectual latinoamericana, que a veces alcanza cimas de productividad: Pedrosa hace la misma operación en espejo con la fórmula de "ciudad artificial", y en este caso es doblemente interesante porque Richard Morse estaba haciendo exactamente lo mismo para la misma época -aunque con algo más de profundidad histórica y radicalidad conceptual. ${ }^{49}$

El otro aporte diferencial al pensamiento urbano que quería señalar de Pedrosa es entonces sobre la "artificialidad": no se trata ya de la aceptación pragmática de Wilheim sobre la necesidad de las "razones políticas" en el caso de la nueva capital, sino de una inversión del sentido negativo que le permitía definir una más general condición americana. Pedrosa partía del contraste establecido por una larga tradición "orgánica", pero lejos de la censura que esta implicaba, él subrayaba la potencialidad de las civilizaciones artificiales en términos de la plasticidad para la modernidad: en este suelo nuevo todo puede comenzar de cero cada vez, porque no carga con el "peso fatal" del pasado. De allí surge su epigrama tan citado: los brasileños, los americanos en general, están "condenados ao moderno". ${ }^{50}$ Es la aceptación eufórica de una condición que Lévi-Strauss acababa de presentar en tono adversativo en Tristes trópicos: "las ciudades americanas -comenzaba su capítulo sobre São Paulo- pasan de la lozanía a la decrepitud sin llegar nunca a ser antiguas"; esa aceptación/inversión tenía una densa tradición vanguardista en Brasil desde el movimiento antropofágico. ${ }^{51}$ Pero Pedrosa es siempre ambivalente: al elegir la palabra "condena" dice algo más que la mera ausencia de elección. Puede leerse como una provocación irónica, pero no deja de señalar también la conciencia del autor de su carga ominosa, de las carencias que esa definición denuncia -ya que, como señaló Otilia Arantes, "as leituras trotskistas the ensinaram que uma onda modernizante, talvez inevitável, podia muito bem agravar relações arcaicas de dominação". ${ }^{52}$

Su posición respecto de la idea de "ciudad artificial" presenta la misma ambivalencia: en un breve texto de 1958 reconocía que "a mais profunda objeção" que se le hacía a Brasilia era "que o seu desenvolvimento não poderá jamais ser "natural"; una objeción "muito séria", porque provenía "de uma concepção de vida fundamental", la de que la actividad social está "presa ao biológico, ao orgânico, à natureza". Pero al mismo tiempo, colocaba esa concepción como "um dos traços mais típicos da mentalidade conservadora, no que tem de melhor e mais profundo". A partir de allí, desarrollaba brevemente la explicación que ya analizamos: la tradición americana, brasileña, colonial, es la de la creación ex novo, y Brasilia es coherente con ella, pero -aquí viene el típico giro de Pedrosa- "sendo destinada a Capital do País", no puede quedar presa de esa tradición, es decir, no puede seguir "vivendo como um oásis, ou colônia fundada sobre base artificial": debe ser "uma antecipação do futuro: uma utopia", en

\footnotetext{
49 Morse lo había hecho en 1956 en una intervención en un panel sobre "Expansión urbana en América Latina en el siglo XIX", en el $71^{\circ}$ Congreso de la American Historical Association. Para él, la artificialidad (noción que recuperaba de los ensayistas latinoamericanos de comienzos del siglo XX), era una condición definitoria de la identidad urbana latinoamericana que debía fundar por la positiva cualquier reflexión sobre la misma: ver Richard Morse, "La ciudad artificial", Estudios Americanos, vol. XIII, núms. 67-68, Sevilla, abril-mayo de 1957. Analicé el tema en: "La 'ciudad latinoamericana' como idea", Punto de Vista № 73 (especial sobre Richard Morse), Buenos Aires, agosto de 2002.

50 Mario Pedrosa, "Reflexões em torno da nova capital" (1957), en Dos murais de Portinari..., op. cit., p. 304. Otilia Arantes (op. cit., p. 89) señaló que, según Pedrosa, la frase la inspiró Blaise Cendrars (lo que convierte al poeta suizo-francés en una suerte de musa transhistórica de las vanguardias brasileñas).

${ }^{51}$ Claude Lévi-Strauss, Tristes trópicos (1955), Buenos Aires, Paidós, 1988, p. 97.

${ }^{52}$ Otilia Arantes, op. cit., p. 102.
} 
una época que por primera vez posibilita "a passagem da utopia ao plano". ${ }^{53}$ La "condena" moderna explica el presente (y el pasado), pero no obliga a un único futuro: para Pedrosa, a través del "plan" se puede arribar a la "formação paulatina de uma cultura orgânica local" -en términos de Guilherme Wisnik-, siendo Brasilia la "indutora de um processo civilizatório novo, orgânico, planejado, e dotado de um verdadeiro caráter regional”. ${ }^{4}$

Ahora bien, el giro que da el texto permite retornar con criterios más ajustados a la expresión "mentalidade conservadora" -un calificativo cuyo uso nunca es azaroso en un intelectual de izquierda-: es claro que Pedrosa compartía el objetivo último, la "cultura orgánica", lo que esa mentalidad conservadora "tem de melhor e mais profundo". Hay que recordar que el regionalismo de Mumford -una de sus referencias fundamentales- confluyó con los movimientos conservacionistas, algo conntaural en el progresismo norteamericano, y que la propia definición de "ciudad ideal moderna" de Pedrosa comparte la omnipresente demanda restauradora del urbanismo y la planificación: "uma estrutura humana através da qual expandirse e restaurar a coesão social perdida". ${ }^{55}$ El problema de una "mentalidade conservadora", en todo caso, su rasgo conservador strictu sensu, sería suponer que la "cultura orgánica" es sólo y siempre el resultado "natural" de una historia milenaria (que sólo se encuentra en el pasado); para el crítico progresista de una nación moderna, en cambio, puede ponérsela como punto de llegada (como utopía).

La paradoja obvia de la definición de Pedrosa -si se pretende tomarla como algo más que una boutade - es que la plasticidad congénita de una nación "condenada ao moderno" al mismo tiempo que le permite proponerse ese futuro, se lo impide -de no mediar, claro está, una fortísima voluntad colectiva en la dirección opuesta a esa misma condena. ¿Podría Brasilia "inducirla"? Pedrosa dejó de escribir sobre la nueva capital muy temprano, poco después de su inauguración, quizás porque ninguna evolución esperable de la construcción de la ciudad iba a poder cumplir con el rol tan crucial que le asignaba en un cambio completo de la tendencia histórico-territorial de Brasil; y ya es posible ver en trechos importantes de sus textos de entonces que advertía varios de los obstáculos para ello: especialmente, la especulación y segregación que yacían detrás de "os vagos projetos de cidades satélites", el tema que organizaría toda la batería de críticas sociológicas de allí en adelante. ${ }^{56}$

No se trata aquí, de todos modos, de hacer un balance de los logros de Brasilia, sino de entender lo que, a la luz de estos dos comentaristas singulares, la nueva capital nos muestra sobre el pensamiento planificador de su tiempo. Así como la noción de "ciudad artificial" empleada por Pedrosa invertía una zona potente del pensamiento occidental, así podríamos decir que Brasilia aparece en las lecturas de ambos como una inversión de la planificación. Una inversión que devolvió la arquitectura a un sitial de honor como disciplina clave en la configuración del ambiente, con capacidad para producir una gramática convincente de la identidad nacional-moderna, y que les permitió a un planificador someter a duda sus propias convicciones, y a un historiador del arte postular una planificación humanista capaz de conjurar la condena de la modernidad.

\footnotetext{
${ }^{53}$ Todos los entrecomillados del párrafo son de "Utopía - Obra de arte", Jornal do Brasil, Rio de Janeiro, 21 de mayo de 1958, reproducido en Mario Pedrosa, Dos murais de Portinari..., op. cit., pp. 317-319.

${ }^{54}$ Guilherme Wisnik, Arquitetura: ensaios críticos..., op. cit., pp. 19-20.

55 "Crescimento da cidade", Jornal de Brasil, Rio de Janeiro, 16 de septiembre de 1959, reproducido en Dos murais de Portinari..., op. cit., p. 299 (subrayado nuestro).

${ }^{56}$ Ver "Brasília, hora de planejar" (1960), en Mario Pedrosa, Dos murais de Portinari..., op. cit., p. 397.
} 


\section{Referencias}

AGUILAR, Gonzalo. El laberinto transparente. La poesía concreta brasileña en la ciudad. Block, $N^{\circ}$ 4, Buenos Aires, UTDT, diciembre de 1999.

ALVIM, Angélica Tanus Benatti, ABASCAL, Eunice Helena Sguizzardi, ABRUNHOSA, Eduardo Castedo (orgs.). Arquitetura Mackenzie 100 anos - FAU-Mackenzie 70 anos: pionerismo e atualidade. São Paulo: Editora Mackenzie, 2017 (ed. online).

ARANTES, Otilia. Mário Pedrosa: Itinerário crítico. São Paulo: Editora Página Aberta, 1991.

BANHAM, Reyner. Guide to Modern Architecture. D. Van Nostrand, 1962.

BENEVOLO, Leonardo. Storia della architettura moderna. Roma: Laterza, 1975 (sexta edición).

BRAGA, Milton. O concurso de Brasília. São Paulo: CosacNaify, 2010.

CAMPOS, Augusto de, PIGNATARI, Décio, CAMPOS, Haroldo de. "Plano-pilôto para poesia concreta". Noigandres, № 4, São Paulo, 1958.

CARPINTERO, Antonio Carlos. Brasília: prática e teoria urbanística no Brasil, 1956-1998. tesis de doctorado FAU-USP, 1998.

CORBISIER, Roland. Brasília e o Desenvolvimento Nacional [1960]. In: XAVIER Alberto, KATINSKY, Julio (orgs.). Brasília - antología crítica. São Paulo: Cosac Naify, 2012.

CORBOZ, André. El urbanismo del siglo XX: un balance [1992]. In: CORBOZ, André. Orden disperso. Ensayos sobre arte, método, ciudad y territorio [1998]. Bernal: Editorial de la Universidad Nacional de Quilmes, 2015.

Editorial (sin firma). Mentalidade de planejamento. Hábitat, № 54, São Paulo, mayo-junio 1959.

FARIA, Rodrigo de, CARPINTERO, Antonio. Brasilia, Capital del Brasil: desarrollo nacional y urbanismo (1930 - 1960). In: SAMBRICIO, Carlos (org.). Ciudad y vivienda en América Latina: 1930-1960. Madrid: Lampreave, 2012.

FELDMAN, Sarah. Planejamento e zoneamento. São Paulo 1947-1972. São Paulo: EDUSP, 2005.

FURTADO, Celso. Obra autobiográfica. São Paulo: Companhia das Letras, 2014 (A fantasia organizada [1985] y A fantasia desfeita [1989]).

GORELIK, Adrián. La 'ciudad latinoamericana' como idea. Punto de Vista, № 73 (especial sobre Richard Morse), Buenos Aires, agosto de 2002.

Sobre a impossibilidade de (pensar) Brasília. Serrote, № 10, Revista del Instituto Moreira Salles. Río de Janeiro, marzo de 2012.

GUEDES, Joaquim. Por uma nova cidade. AU, № 2, São Paulo, abril 1985.

HOLANDA, Frederico de. O espaço de exceção. Brasilia: Editora Universidade de Brasília, 2012.

ILPES. Planificación regional y urbana en América Latina. México: Siglo XXI Editores, 1974.

KUBITSCHEK, Juscelino. Entrevista. Modulo, № 4, Río de Janeiro, mayo de 1956.

LAFER, Celso. JK e o Programa de Metas (1956-1961): processo de planejamento e sistema político no Brasil. Río de Janeiro: Editora FGV, 2002. 
LANER, Izadora Carvalho. Planejamento regional e desenvolvimento no Brasil: 1955-1961. Tesis de Maestría, Faculdade de Arquitetura, Universidade de Brasilia, 2018.

LÉVI-STRAUSS, Claude. Tristes trópicos (1955). Buenos Aires: Paidós, 1988.

LOBO, Maria da Silveira, SEGRE, Roberto (orgs.). Congresso Internacional de Críticos de Arte. Cidade nova: síntese de artes. Rio de Janeiro: UFRJ-FAU, 2009.

MARQUES NETO, José Castilho (org.). Mario Pedrosa e o Brasil. São Paulo: Editora Fundação Perseu Abramo, 2001.

MARTINS, Carlos. 'Hay algo de irracional...' Apuntes sobre la historiografía de la arquitectura brasileña. Block 4, Buenos Aires, UTDT, diciembre de 1999.

MATTOS, J.M.A de Almeida. "A mirabolante nova capital brasileira". Brasil Arquitetura Contemporânea, № 9, Río de Janeiro, 1957.

Editorial. Brasil Arquitetura Contemporânea, № 10, Río de Janeiro, 1957.

MORSE, Richard. La ciudad artificial. Estudios Americanos, vol. XIII, núms. 67-68, Sevilla, abrilmayo de 1957.

NOBRE, Ana Luiza. Fios cortantes. Projeto e produto, arquitetura e design no Rio de Janeiro. Tesis de doctorado, Departamento de História, PUC-Río, 2008, p. 44.

PEDROSA, Mario. Dos murais de Portinari aos espaços de Brasília. In: Mundo, Homem, Arte em Crise. AMARAL, Aracy (org.). São Paulo: Perspectiva, 1981.

A arquitetura moderna no Brasil. Conferencia publicada en L'Architecture d'Aujurd'Hui, diciembre de 1953. In: Mundo, Homem, Arte em Crise. AMARAL, Aracy (org.). São Paulo: Perspectiva, 1981.

Reflexões em torno da nova capital (1957). In: Mundo, Homem, Arte em Crise. AMARAL, Aracy (org.). São Paulo: Perspectiva, 1981.

O depoimento de Oscar Niemeyer(1958). In: Mundo, Homem, Arte em Crise. AMARAL, Aracy (org.). São Paulo: Perspectiva, 1981.

"Utopía "“ Obra de arte”, Jornal do Brasil, Rio de Janeiro, 21 de mayo de 1958. In: Mundo, Homem, Arte em Crise. AMARAL, Aracy (org.). São Paulo: Perspectiva, 1981.

Nuvens sobre Brasília, artículo del 13 de junio de 1958. In: Mundo, Homem, Arte em Crise. AMARAL, Aracy (org.). São Paulo: Perspectiva, 1981.

Crescimento da cidade, Jornal de Brasil, Rio de Janeiro, 16 de sep. de 1959. In: Mundo, Homem, Arte em Crise. AMARAL, Aracy (org.). São Paulo: Perspectiva, 1981.

Brasília, a cidade nova, comunicación presentada en el Congreso Internacional de Críticos, Brasilia, septiembre de 1959. In: Mundo, Homem, Arte em Crise. AMARAL, Aracy (org.). São Paulo: Perspectiva, 1981.

Brasília, hora de planejar (1960). In: Mundo, Homem, Arte em Crise. AMARAL, Aracy (org.). São Paulo: Perspectiva, 1981.

PFEIFER, Gottfried. Remarques de M. Pfeifer. Symposium sur Brasilia, Caravelle. Cahiers du monde hispanique et luso-brésilien, № 3, Tolouse, 1964.

PIRENNE, Henri. Las ciudades de la Edad Media (1927). Madrid: Alianza Editorial, 1972.

ROCHE, Jean. Exposé introductif. Symposium sur Brasilia, Caravelle. Cahiers du monde hispanique et luso-brésilie, $n$ № 3, Tolouse, 1964. 
SANTOS, Milton. Brasília, a nova capital brasileira. Symposium sur Brasilia, Caravelle. Cahiers du monde hispanique et luso-brésilien, № 3, Tolouse, 1964.

SOUZA, Candice Vidal e. A pátria geográfica. Sertão e litoral no pensamento social brasileiro. Editora UFG, Goiânia, 1997.

TAVARES, Jeferson. Projetos para Brasília: 1927-1957. Brasilia, Iphan, 2014.

WILHEIM, Jorge. Brasília 1960. Uma interpretação. Acrópole, 256/257, São Paulo, 1960.

Brasília 1969: um comentário indispensável. In: WILHEIM, Jorge. Urbanismo no subdesenvolvimento. Rio de Janeiro: Editôra Saga, 1969.

WISNIK, Guilherme. Modernidade congénita. In: ANDREOLI, E., FORTY, A. Arquitetura moderna brasileira. Londres/Nueva York: Phaidon, 2004.

Brasília 50 anos: trilha torta por linhas certas. BRAGA, Milton. O concurso de Brasília. São Paulo: CosacNaify, 2010.

Apresentação. In: PEDROSA, Mário. Arquitetura: ensaios críticos. São Paulo: Cosac Naify, 2015.

ZEVI, Bruno. Inchiesta su Brasilia. Sei [questione] sulla nuova capitale sudamericana. L'architettura. Cronache e Storia, № 51, Milán, enero de 1960.

\section{Adrián Gorelik}

(Mercedes, Buenos Aires, 1957) es arquitecto y doctor en historia (ambos títulos por la Universidad de Buenos Aires). Es investigador del CONICET y profesor titular de la Universidad Nacional de Quilmes. Recibió la Beca Guggenheim, fue profesor Simón Bolívar de la University of Cambridge y miembro del Wissenschaftskolleg de Berlín. Actualmente es parte del grupo editor de Prismas. Revista de historia intelectual. Libros principales: La sombra de la vanguardia. Hannes Meyer en México, con Jorge F. Liernur (Buenos Aires, 1993; nueva edición aumentada en Santiago de Chile, 2019); La grilla y el parque. Espacio público y cultura urbana en Buenos Aires (Buenos Aires, 1998), Miradas sobre Buenos Aires (Buenos Aires, 2004) y Das vanguardas a Brasília. Cultura urbana e arquitetura na América Latina (Belo Horizonte, 2005). Editó junto con Fernanda Peixoto, Ciudades sudamericanas como arenas culturales (Buenos Aires 2016 y Sao Paulo 2019).

Como citar: GORELIK, Adrián. Brasilia en el Espejo de la Planificación. Revista Paranoá. n.29, jan/jun 2021. DOI 10.18830/issn.1679-0944.n29.2021.04

Editoras responsáveis: Maria Fernanda Derntl e Carolina Pescatori 